\title{
An Adaptive Intelligent Presentation Edugame for Fardu Ain Learning Using Production Rules Based on User Emotions
}

\author{
Rahmah Mokhtar and Nor Azan Mat Zin
}

\begin{abstract}
An Edugame mobile application namely, Fardhu Ain Firdaus is an intelligent personalization edugame application for kids to learn Wudhu and Solah. This edugame used mobile platform that embedded the Production Rules intelligent technique for emotion prediction and presentation. The objectives of this research are to investigate limitation and parameter of adaptive rules based on emotions characteristics, to produce new rules for emotion solving in mobile edu games adaptive presentation and to test the accuracy of production rules for emotion solving in mobile edu games. The app interface will change according to the mood of the kids and ease their negative emotions and make the children ready to accept the learning and knowledge. This app can overcome "one size fits all" problem in app's games available by embedding the personalization into the apps. User acceptance tests have been done to 10 children, and results showed that this edugame app could enhance their understanding and attract them towards learning Fardhu Ain. This edugame technology personalization application can be new attraction to the computer games' lover.
\end{abstract}

Index Terms-Adaptation Edugame, edugame, emotions in teaching and learning.

\section{INTRODUCTION}

Edugame is the games that combines pedagogical and entertainment in one application. Edugame are designed for the purpose of contributing to the teaching and learning [1], as nowadays the approach of teaching and learning is change into the usage of multimedia [2]. Various subjects can be delivered using this new approach includes language learning. Multimedia is shown as one of an effective way to attract the student to perceive the knowledge [3]. The use of interactive multimedia such as Edugame, provides the authentic learning experiments, learners' control over their learning and focus on the content [4]. This will gives new exciting way for the student to learn and the teacher to teach the subject.

Recently, Edugame on mobile devices is growing rapidly and in great demand by students for entertainment or increase their knowledge. The Edugame is use to enhance interested learning and entertaining to various aspects of education [5]. The best identified aspects of the Edugame is to increases the motivation of learners [6] and the relationship between games and constructivist theory [7], because the games are well made can have pedagogical value of learning to produce a

Manuscript received March 11, 2016; revised August 12, 2016.

R. Mokhtar is with Universiti Malaysia Pahang, Malaysia (e-mail: drrahmah@ump.edu.my).

Nor Azan Mat Zin is with Universiti Kebangsaan Malaysia, Malaysia (e-mail: azan@ukm.edu.my). satisfactory outcome. A crucial factor for adaptivity is challenge. It can result from adapting the level of difficulty of the tasks to the learners' ability level so that a constant challenge is felt. Not only the level of difficulty of the tasks is adjusted to the learners' ability level, but also the system reacts to personal learning styles, preferences and emotions [8].

This paper will present an adaptive Edugame based on Emotion for Fardhu Ain Learning.

\section{A. Related Works}

Edugame have become common domestic and personal technologies and become pervasive feature on any multimedia devices, particularly in mobile phone. The well designed Edugame here the potential advantage of increasing intrinsic motivation and deeping learning [1]. The informal literacies that are developed through Edugame make them of interest and value to educators in informal teaching and learning [9]. [10] stated that the key to successfully implementing Edugame involves developing a strong alignment between the Edugame development process, the topic/subject, the arrival and the experience of the individual student. It involves a critical understanding of the relationship between player and pedagogy way informs curriculum developer.

There are a few adaptation types such as context-aware system, which adapted the presentation of the content. Content was presented in a variety of ways based on both student prior competencies (pre-requisite knowledge and skills) and preferences [11].

Research by [12] shows how Emotions play an extremely important role in human life. It can acts as a good decision making by combining emotion with head and heart together to make the right decision. Emotions show feeling and helps human to recognize the truth, appreciate beauty and gives human the experience of joy. It is shown that emotions can enhance the learning capabilities in human and should be an important aspect to be considered in adaptation technology.

\section{An AdAPtive InTELligent PRESENTATION EDUGAME BASED ON EMOTIONS}

An adaptive intelligent presentation edugame based on emotions is an educational game, which used intelligent production rules base on emotion characteristics of the user to present the content of the game. Emotions are the aspect of adaptation for this game. To test the rules and adaptation that can be embedded into the games technology, the researcher 
develops a prototype, namely Fadhu Ain Firdaus mobile game.

\section{A. The Development}

Fig. 1 shows the framework flow of emotion detection and content presentation in Fardhu Ain Firdaus application. Its starts when an application is able to detect the result from the user based on the questionnaire given through the interface. Then the system will check the rules for emotions. After the system detect the emotions based on user selection, it will be matched the suitable presentation to suit the user's need and the interface of solution is appearing to the users.

The process of emotion detection will stopped after the system did not receive any response (clicking the emotion icon) by the user. The presentation interface will remain the same.

The application can be considered as real time application as every time the user clicks the emotion icon, the interface will keep on changing based on the user's emotion.

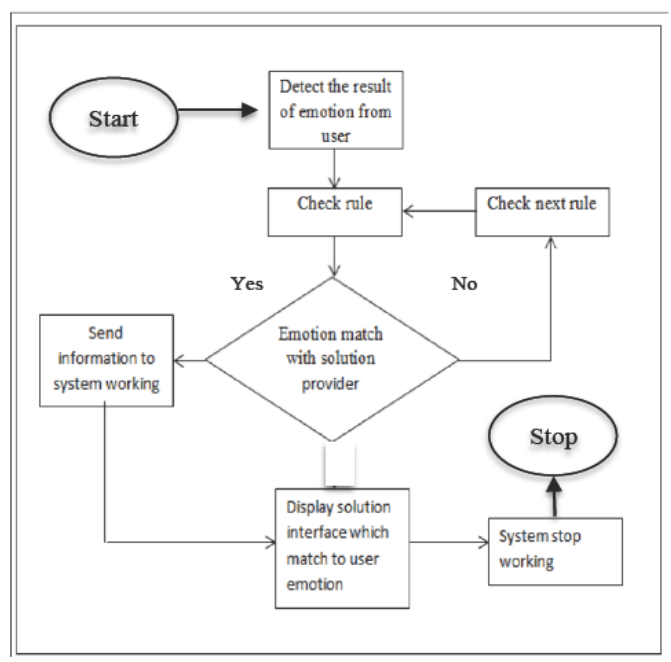

Fig. 1. Application frameworks.

\section{B. Rule of Adaptive Emotions}

Fardhu Ain Firdaus application is an edugame that used context-aware system to adapt the content as emotion solving in mobile environment. A set of rules for adaptive emotions solving is created, as shown in Fig. 2. The system will be able to adapt the emotions using Production rules. Based on the identification, information can be obtained from student's emotions through questionnaire. Then, the application offers content that are adaptive to the emotion and students can ease their feeling while perceive the knowledge.

Based on the rules, the user will interact with the interface as shown in Fig. 3. The user will click on the icon that represents their feeling. If the "HAPPY" icon is selected, then the happy presentation will be shown to the user.

\section{The Interface Design}

Interface design plays, a crucial part in adaptive application. Through the interface, interaction between user and the application occurs. The application systems will be able to detect the emotion through the questionnaire given by the application. The design of user emotion detection through questionnaire is shown in Fig. 3.

Ref. [13] identified the emotions could be relieve by using the color aura. The color aura based on the expert [13], have been simplified and shown in Table 1. For sad emotion, the design of interface must have lots of green color. The green color will stimulate the emotion to feel happy and be in neutral environment. Furthermore for happy emotion, the interface must have lots of pink color. This is because the pink color will sustain the happy emotion. While for the angry emotion, the design should have lots of blue color. The blue color will ease the angry emotion.

If the user is detected with the sad emotion, the content of sad, which full of green color interface will be presented to the user. The color of green is determined by [13] as an aura to ease the sad emotion. The sad interface is shown in Fig. 4.

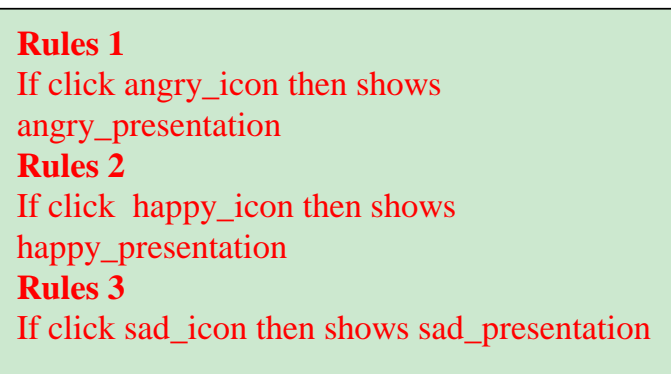

Fig. 2. Set of rules for adaptive presentation.

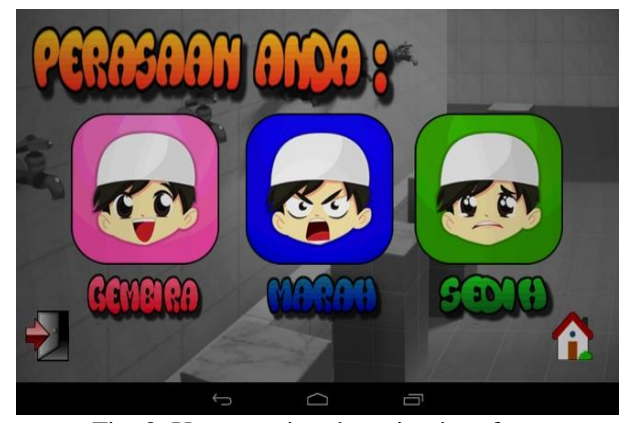

Fig. 3. User emotion detection interface.

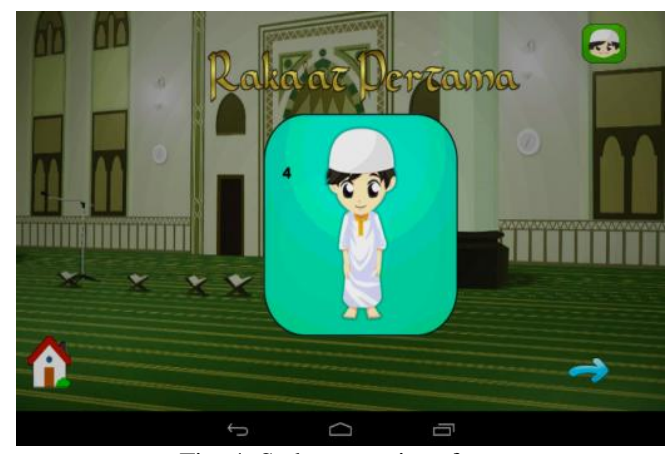

Fig. 4. Sad content interface.

TABLE I: MAIN COLOR TO EASE EMOTION

\begin{tabular}{|l|l|}
\hline Emotion & Main Color to Ease Emotion \\
\hline Sad & Green \\
\hline Happy & Pink \\
\hline Angry & Blue \\
\hline
\end{tabular}

\section{TeSTING AND RESUlt}

\section{A. Testing}

The researcher has done the usability test based on the 
Edugame application, namely Fardhu Ain Firdaus. The objectives of this test it to see the effectiveness of the respondents towards the application. Ten children aged six to nine years old are being selected as respondents. As this is a qualitative research, ten respondents is enough to shows the result that will fulfill the objective of the testing. They have been given the application to play with. The emotion icon chosen is also been control by the observation of the researcher throught the children face and attitude reaction. This is to make sure that the children are selecting the right emotion that's show their feeling.

\section{B. Results}

The result is divided in to four categories, which is shows the look and feel of the application, the ease of use, the color influence and the learn ability.

Fig. 5 shows the look and feel of the children towards the application. Each percentage shows that the children loves the look and feel of this application with $100 \%$ result acceptance based on cumulative of the look and feel percentage.

The ease of use results shown $93 \%$ acceptance by the user as referred to Fig. 6.

$7 \%$ of the respondents is detecting as a new user to the mobile technology and take an extra time to learn and get use of the mobile game application.

Fig. 7 illustrates the bar charts that show the $100 \%$ of the respondents agree the application color, influence their emotion and enhance their learning ability.

As the result discussion, its shows that an adaptive intelligent presentation edugames using production rules based on user emotions can be used to enhance the learning capability of the children while perceive their learning through edugames.

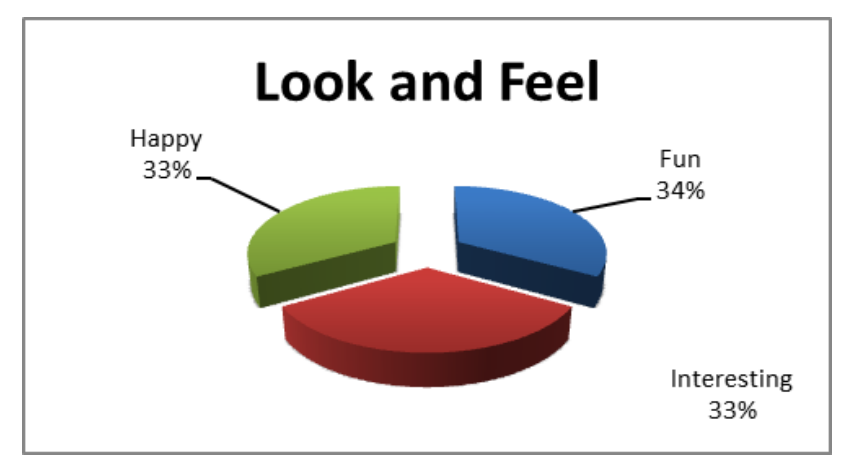

Fig. 5. Look and feel result.

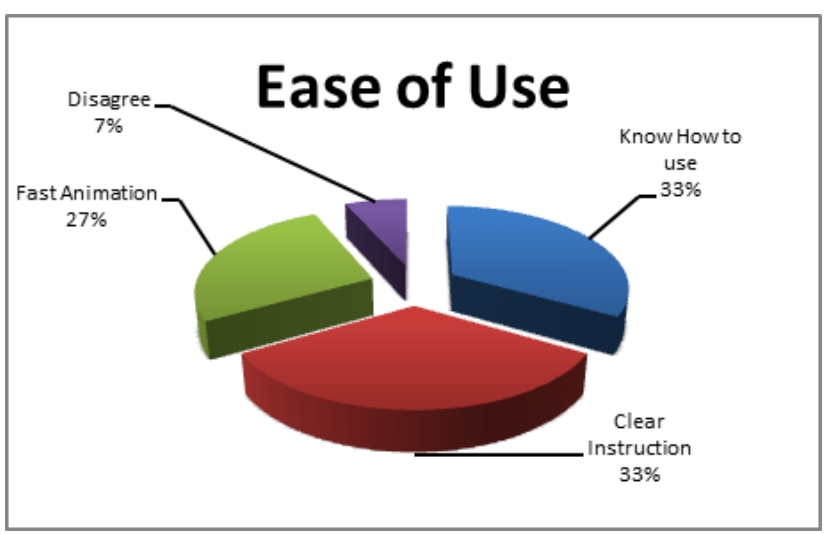

Fig. 6. Look and feel result.

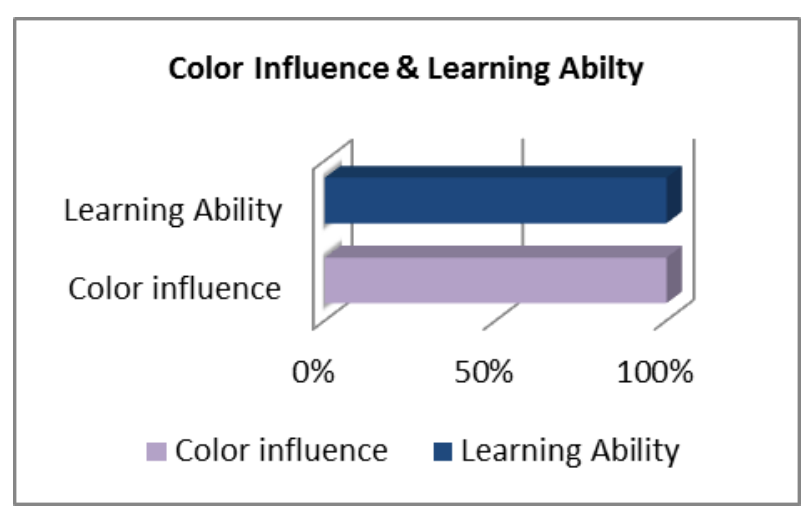

Fig. 7. The acceptance result of edugame usage.

\section{CONCLUSION}

The adaptive technology based on emotions can helps the learner to perceive the knowledge easily. The capability of color aura can ease the learner's emotion and makes their acceptance of learning smoothly without any distraction of negative emotions. All Edugame developer can use this technology to developed personalized intelligent Edugame. The future work of this study is to attach the application with Brain Computer Interface, which can automatically predict the user emotion and match the emotion to suitable interface presentation.

\section{ACKNOWLEDGMENT}

The authors wish to thank all the individual and organization who involve in this research and special thanks to University Malaysia Pahang and Ministry of Higher Education for funded this research under RACE Gantt (RDU 141304).

\section{REFERENCES}

[1] P. Benson and A. Chik, Popular Culture, Pedagogy and Technology, New York: Routledge Pub., 2014, p. 243.

[2] M. Al-Otaibi et al., Effects of Multimedia Activities in Blended Learning on Listening Skill and Satisfaction in a Collage English Learning Course, INTED, 2012.

[3] K. Geza, "Multimedia for language learning," Diss. Massachusetts Institute of Technology, p. 211, 2013.

[4] M. Z. Norazan et al., "Penilaian perisian kursus adaptif Multimedia (A-Maths) Berasaskan Stail Pembelajaran," Jurnal Teknologi Maklumat dan Multimedia, vol. 5, pp. 61-78, 2009.

[5] W. Nicola, "Encouraging engagement in game-based learning," International Journal of Game-Based Learning, vol. 1, no. 1, pp. 75-84, 2011.

[6] S. Brett, "Historical perspectives on games and education from the learning sciences," International Journal of Game-Based Learning, vol. 1, no. 3, pp. 83-106, 2010.

[7] T. Glushkova, "Adaptive model for user knowledge in the e-learning system," in Proc. International Conference on Computer Systems and Technologies, pp. 161-166, 2008.

[8] F. Spring-Keller and H. Schauer, "Adaptive game-based learning," in Proc. the IFIP Workgroup 3.1, 3.3, 3.5 Joint Conferences, 1993.

[9] Information Science and Management Engineering II, WIT, Transaction on Information and communication Technologies, vol. 62, 2014.

[10] Jonathan, Education Psychology: Cognition and Learning Individual Differences and motivation, Nova Science Publisher, p. 287, 2009.

[11] Jonathan, Education Psychology: Cognition and Learning individual Differences and Motivation, Nova Science Publisher, 2009.

[12] R. Pekrun et al., Positive Emotions in Education in Beyond Coping, Meeting Goals, Visions and Challenges, Oxford: Oxford University Press, pp. 149-173, 2010.

[13] M. Hazil, A. P. Warna, and K. Lumpur, PTS, p. 185, 2010. 


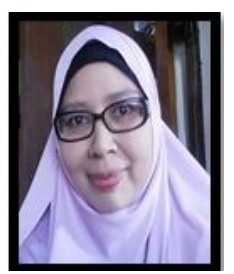

Rahmah Mokhtar is a senior lecturer at the Faculty of Computer Systems and Software Engineering, Universiti Malaysia Pahang (UMP), Malaysia. Currently she is being appointed as the head of Multimedia and Graphics Technology Programme. She received her Phd. in information technology, 2011 from National University of Malaysia. Her research interests are in e-learning, information retrieval, internet and mobile technology. She also has involved in architecting the national IT project called MyGRANTS and various involvement on IT projects in UMP. Recently she has presented a research paper on mobile application in International conference.

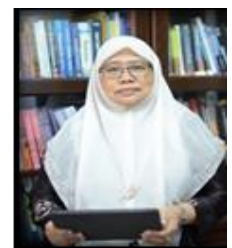

Nor Azan Mat Zin is a senior lecturer at the Faculty of Information Science and Technology and the head of Multimedia Studies and Usability Research. Her specialization is in ICT/multimedia application (games, edutainment) advance learning technology intelligent/adaptive web-based educational system, HCI (accessibility and developmental IC). 